\title{
Effects of Ginger Phenylpropanoids and Quercetin on Nrf2-ARE Pathway in Human BJ Fibroblasts and HaCaT Keratinocytes
}

\author{
Ermin Schadich, ${ }^{1}$ Jan Hlaváč, ${ }^{1,2}$ Tereza Volná, ${ }^{1}$ Lakshman Varanasi, ${ }^{1}$ \\ Marián Hajdúch, ${ }^{1}$ and Petr Džubák ${ }^{1}$ \\ ${ }^{1}$ Institute of Molecular and Translational Medicine, Faculty of Medicine, Palacký University, Olomouc, Czech Republic
}

${ }^{2}$ Department of Organic Chemistry, Faculty of Science, Palacký University, Olomouc, Czech Republic

Correspondence should be addressed to Petr Džubák; dzubakp@gmail.com

Received 28 October 2015; Accepted 29 December 2015

Academic Editor: Paul J. Higgins

Copyright (C) 2016 Ermin Schadich et al. This is an open access article distributed under the Creative Commons Attribution License, which permits unrestricted use, distribution, and reproduction in any medium, provided the original work is properly cited.

Quercetin and phenylpropanoids are well known chemoprotective compounds identified in many plants. This study was aimed at determining their effects on activation of Nuclear factor erythroid 2-related factor 2 (Nrf2) antioxidant response element (Nrf2-ARE) signalling pathway and expression of its important downstream effector phase II detoxification enzyme glutathioneS-transferase P1 (GSTP1) in BJ foreskin fibroblasts and skin HaCaT keratinocytes. Cell lines and their corresponding Nrf2ARE luciferase reporter cells were treated by ginger phenylpropanoids and quercetin for $10 \mathrm{~h}$ and the level of Nrf2 activity was subsequently determined. Both, ginger phenylpropanoids and quercetin, significantly increased the level of Nrf2 activity. Subsequent western blot analyses of proteins showed the increased expression level of glutathione-S-transferase P1 (GSTP1) in BJ cells but not in $\mathrm{HaCaT}$ cells. Such phenomenon of unresponsive downstream target expression in HaCaT cells was consistent with previous studies showing a constitutive expression of their GSTP1. Thus, while both ginger phenylpropanoids and quercetin have the property of increasing the level of $\mathrm{Nrf} 2$ both in $\mathrm{HaCaT}$ and in $\mathrm{BJ}$ cells, their effects on its downstream signalling were mediated only in BJ cells.

\section{Introduction}

As human skin is repeatedly exposed to excessive level of UV radiation and environmental pollutants; protection of its cells against toxic agents depends on an elaborated antioxidant defense system of enzymes and antioxidants for neutralization of induced reactive oxygen species (ROS), biotransformation and elimination of electrophilic species, and maintenance of redox homeostasis $[1,2]$. The involved enzymes are constitutively and inducibly expressed, and, among them, the most significant phase II detoxification enzymes are NADPH oxidoreductase, aldoketo reductase, glutamate-cysteine ligase, and glutathione-S-transferase P1 (GSTP1) $[3,4]$. Their inducible expression in skin cells during antioxidant responses is directly or indirectly regulated by the protein transcription factor named Nuclear factor erythroid 2-related factor 2 (Nrf2) $[5,6]$. The Nrf2, upon its activation by ROS and electrophilic species, translocates into nucleus, heterodimerizes with the small Maf transcription factor, and activates their expression by binding to the cis-acting antioxidant response element (ARE) DNA sequence in the promoters of genes encoding them $[3,7]$.

Under quiescent conditions, the Nrf2 is associated with its cytosolic repressor kelch-like $\mathrm{ECH}$-associated protein 1 (KEAP1) in the Nrf2-KEAP1 complex that promotes its ubiquitination and proteasome degradation $[7,8]$. The KEAP1 acts as a redox sensor and different alterations in its structure induced by ROS and electrophilic compounds including oxidative modifications of its cysteine residues (Cys151, Cys273, and Cys288) lead to its dissociation from this complex and activation of Nrf2 [7-9].

Plant phenylpropanoids identified in ginger plant (Zingiber officinale), 6-gingerol, and 6-shogaol and their derivatives and plant flavonoid quercetin as well as other dietary plant phenolic compounds are considered as chemopreventive candidates against oxidative stress and cancer due to its property of activating Nrf2-ARE signalling pathway in different types of human cells [9-12]. Their effects on 
expression of GSTP1 enzyme could be specifically beneficial in biotransformation of ROS and electrophilic species. However, their ability to activate the Nrf2-ARE pathway and expression of GSTP1 enzyme has not been tested in vitro in human skin cells, including the immortalized keratinocytes ( $\mathrm{HaCaT})$ cells and foreskin fibroblasts (BJ) that are frequently used in various in vitro studies. These cell lines are frequently used as a paradigm of skin cells due to their phenotypic stability and well preserved differentiation capacity [13]. The aim of this study is to determine the effects of ginger phenylpropanoids and quercetin on activation of the Nrf2-ARE signalling pathway and expression of phase II detoxification enzyme glutathione-S-transferase P1 (GSTP1) in HaCaT and BJ cells.

\section{Material and Methods}

2.1. Cell Lines and Luciferase Cell Reporters. HaCaT cells and BJ foreskin fibroblast were obtained from American Type Culture Collection (ATCC). The stable reporter cell lines were obtained by transduction of $\mathrm{HaCaT}$ and $\mathrm{BJ}$ cells with Cignal lentiviral particles with ARE reporters using Qiagen kits (CLS-2020L and CLS-013L). Clones were selected and validated according to instructions provided by manufacturer.

2.2. Preparation of Ginger Extract. The methanol extract of ginger phenylpropanoids was prepared from commercial powder of rhizome of ginger plant (Zingiber officinale) (Vitana). The extraction was done by dissolving $40 \mathrm{~g}$ of powder in $200 \mathrm{~mL}$ of methanol or distilled deionized water and incubated at room temperature for $24 \mathrm{~h}$ with shaking at $120 \mathrm{rpm}$. After extraction, the solids were removed by centrifugation at $3000 \mathrm{~g}$ at $25^{\circ} \mathrm{C}$ for $10 \mathrm{~min}$ and filtration with $0.22 \mu \mathrm{m}$ membrane filter. Subsequently, the methanol extract was dried out using SpeedVac (Thermo Scientific) at $45^{\circ} \mathrm{C}$, dissolved in dimethyl sulfoxide (DMSO), sterilized using $0.22 \mu \mathrm{m}$ membrane filter, and stored at $-80^{\circ} \mathrm{C}$.

\subsection{Ultrahigh Performance Liquid Chromatography Analy-} ses of Phenylpropanoids. The ultrahigh performance liquid chromatography (UHPLC) analyses of ginger extract were performed using Waters UHPLC system as described in previous studies [14-16]. Ginger extract had a concentration of $0.2 \mathrm{mg} / \mathrm{mL}$ in $100 \%$ DMSO. The separation was carried out on X-Select C18 reversed phase column $(3.0 \times 50 \mathrm{~mm}$; $2.5 \mu \mathrm{m})$ at $30^{\circ} \mathrm{C}$ using a flow rate of $600 \mu \mathrm{L} / \mathrm{min}$. Mobile phase $\mathrm{A}$ was $0.01 \mathrm{M}$ ammonium acetate in water and mobile phase B was $100 \%$ acetonitrile. The elution cycle had a linear gradient from $80 \% \mathrm{~A}$ and $20 \% \mathrm{~B}$ to $20 \% \mathrm{~A}$ and $80 \% \mathrm{~B}$ over the period of $2.5 \mathrm{~min} .80 \% \mathrm{~B}$ was maintained over the $1.5 \mathrm{~min}$ interval. The column was reequilibrated at $10 \% \mathrm{~B}$ for $1 \mathrm{~min}$. Absorbance of HPLC peaks was measured using a photodiode array (PDA) detector, and the area under each peak (AUC) was used to determine relative compound content and purity. Detection of molecular ions was performed using single quadrupole mass spectrometer (Waters) fitted with an electrospray ionization source for negative and positive ion modes. The atmospheric pressure chemical ionization operated at a discharge current of $5 \mu \mathrm{A}$, vaporizer temperature of $350^{\circ} \mathrm{C}$, and capillary temperature of $200^{\circ}$ C. System is controlled by MASSLYNX (version 4.1) software.

2.4. MTT Cytotoxic Assay. The BJ and HaCaT cells were maintained in Nunc/Corning $80 \mathrm{~cm}^{2}$ plastic tissue culture flasks and cultured in cell culture medium (Minimum Essential Media (Sigma-Aldrich)) supplemented by $1 \%$ nonessential amino acids (NEAA), $1 \mathrm{mM}$ sodium pyruvate, $10 \% \mathrm{FCS}$, streptomycin $(100 \mu \mathrm{g} / \mathrm{mL})$, and penicillin $(100 \mathrm{IU} / \mathrm{mL})$. Cell suspensions were prepared and diluted target cell density (10000 cells/well). Cells were added by pipette $(80 \mu \mathrm{L})$ into 96-well microtiter plates. Inoculates were allowed a preincubation period of $24 \mathrm{~h}$ at $37^{\circ} \mathrm{C}$ and $5 \% \quad \mathrm{CO}_{2}$ for stabilization. Fourfold dilutions, in $20 \mu \mathrm{L}$ aliquots, of the intended test concentration were added to the microtiter plate wells at time zero. All test compound concentrations were examined in duplicate. Incubation of the cells with the test compounds lasted for $72 \mathrm{~h}$ at $37^{\circ} \mathrm{C}$ and $5 \% \mathrm{CO}_{2}$. At the end of the incubation period, the cells were assayed using MTT. Aliquots $(10 \mu \mathrm{L})$ of the MTT stock solution were pipetted into each well and incubated for further $2 \mathrm{~h}$. After this incubation period the formazan produced was dissolved by the addition of $100 \mu \mathrm{L} /$ well of $10 \%$ aq SDS ( $\mathrm{pH}$ $5.5)$, followed by a further incubation at $37^{\circ} \mathrm{C}$ overnight. The optical density (OD) was measured at $560 \mathrm{~nm}$ by EnSpire multimode plate reader (PerkinElmer). Cell survival (IC50) was calculated using the following equation: $\mathrm{IC}=(\mathrm{ODd}$ rugexposed well/mean ODcontrol wells) $\times 100 \%$. The IC50 value, the drug concentration lethal to $50 \%$ of cells, was calculated from appropriate dose-response curves.

2.5. Luciferase Assays. BJ and $\mathrm{HaCaT}$ reporter cells were seeded in white 96-well plates (PerkinElmer) at concentration of $2 \times 10^{5}$ in $100 \mu \mathrm{L}$ of Minimum Essential Media (Sigma-Aldrich) supplemented by $1 \%$ nonessential amino acids (NEAA), $1 \mathrm{mM}$ sodium pyruvate, 10\% FCS, streptomycin $(100 \mu \mathrm{g} / \mathrm{mL})$, and penicillin $(100 \mathrm{IU} / \mathrm{mL})$ for $24 \mathrm{~h}$ at $37^{\circ} \mathrm{C}$ and $5 \% \mathrm{CO}_{2}$. The media was replaced by OptiMEM media (Gibco) containing 0.5\% FBS and 1\% NEAA and cells were treated by $40 \mu \mathrm{g} / \mathrm{mL}$ of ginger extract or $30 \mu \mathrm{M}$ quercetin (Sigma-Aldrich) while the control wells contained media with corresponding concentration of the solvent $0.05 \%$ dimethyl sulfoxide (DMSO) as described by Bak et al. [17]. Following $10 \mathrm{~h}$ treatment, the cells were lysed by $20 \mu \mathrm{L}$ of cell culture lysis buffer (E153A, Promega) and $100 \mu \mathrm{L}$ of luciferase assay substrate (E1483, Promega) was added. Luminescence was measured by EnSpire multimode plate reader (PerkinElmer). The values from luminescence assays were normalized by values acquired from MTT (3-(4,5-dimethylthiazol-2-yl)-2,5-diphenyltetrazolium bromide) assays with the cells that were prepared simultaneously with the same treatment conditions as described by Yamazaki et al. [18]. All the assays were performed three times with five technical replicates for each treatment.

2.6. Western Blot Analyses. For western blot analyses of GSTP1 protein, BJ and $\mathrm{HaCaT}$ cells were grown to confluence 
TABLE 1: Phenylpropanoids identified by UHPLC-MS.

\begin{tabular}{|c|c|c|c|c|}
\hline Peak & Compound & Retention time (min) & MW & $\operatorname{AUC}(\%)$ \\
\hline 1 & [8]-Paradol & 2.10 & 306 & 2.3 \\
\hline 2 & [6]-Gingerdiol & 2.69 & 296 & 3.8 \\
\hline 3 & [6]-Gingerol & 2.86 & 294 & 33.2 \\
\hline 4 & [8]-Gingerol & 3.45 & 322 & 4.4 \\
\hline 5 & Methyl [6]-gingerol & 3.51 & 308 & 3.0 \\
\hline 6 & [6]-Shogaol & 3.61 & 276 & 31.2 \\
\hline 7 & Methyl 3- or 5-acetoxy-[6]-gingerdiol & 3.92 & 352 & 7.3 \\
\hline 8 & {$[10]-$ Gingerol } & 4.03 & 350 & 7.8 \\
\hline 9 & Methyl diacetoxy-[8]-gingerdiol & 4.13 & 422 & 4.7 \\
\hline 10 & [12]-Gingerdione & 4.24 & 376 & 2.5 \\
\hline
\end{tabular}

Note: AUC was calculated from Sum HPCL-PDA chromatogram $(230-370 \mathrm{~nm})$.

in $100 \mathrm{~mm}$ petri dish and media were replaced by treatment media solutions with $40 \mu \mathrm{g} / \mathrm{mL}$ of ginger phenylpropanoids or $30 \mu \mathrm{M}$ of quercetin while control dish contained media with $0.05 \%$ DMSO for $10 \mathrm{~h}$ treatments. The protein lysates were obtained by lysis of cells with NP-40 lysis buffer (1\% NP40, $10 \mathrm{mM}$ Tris, $\mathrm{pH} 7.5,150 \mathrm{mM} \mathrm{NaCl}, 0.05 \mu \mathrm{M}$ dithiothreitol, $1 \mathrm{x}$ phosphatase, and protease inhibitor cocktails (Roche)) following $30 \mathrm{~min}$ incubation on ice and its clarification by centrifugation at $14000 \mathrm{~g}$ at $4^{\circ} \mathrm{C}$ for $10 \mathrm{~min}$. Western blot analyses were performed according to procedures described by Hrabakova et al. [19]. The proteins $(50 \mu \mathrm{g})$ were resolved on a $12 \%$ SDS-PAGE gel prior to membrane transfer. Blots were incubated with rabbit polyclonal anti-GSTP1 antibody (Immunotech) at a concentration of $1: 100$ overnight at $4{ }^{\circ} \mathrm{C}$ and the GSTP1 bands of $23 \mathrm{kDa}$ were visualised using secondary antibody (Alexa Fluor 488 goat anti-rabbit IgG). The membrane was stripped by incubation in stripping buffer $(2 \%$ SDS, $6.25 \mathrm{mM}$ Tris-Cl pH 6.8, $100 \mathrm{mM} \beta$-mercaptoethanol) for $30 \mathrm{~min}$ at $50^{\circ} \mathrm{C}$ and washed five times using wash buffer (0.1\% Tween $20,1 \mathrm{x}$ TBS). The stripped blots were reprobed by mouse monoclonal anti- $\beta$-actin antibody (Sigma) at concentration $1: 10000$ and the actin bands of $42 \mathrm{kDa}$ were visualised by secondary antibody anti-mouse Ig FITC conjugate. The intensities of detected GSTP1 protein bands were quantified using Image J system and normalized by the intensity of actin bands. The data from three independent protein samples were used for analyses.

2.7. Statistical Analyses. The significant differences in production of signals between luciferase of treated Nrf2 reporter cells controls and the significant difference in intensity of downstream target protein bands of treated parental cells were determined by independent $t$-test with an alpha level of 0.025 , following Bonferroni's correction. All analyses were performed with STATISTICA software package.

\section{Results}

3.1. Phenylpropanoid Components of Ginger Extract. The ultrahigh performance liquid chromatography analyses of ginger extract identified compounds with absorbance at 230, 280, and $370 \mathrm{~nm}$ and molecular weights corresponding to those of ten different ginger phenylpropanoids: [6]-gingerol, [8]-gingerol, [10]-gingerol, methyl [6]-gingerol, [6]-gingerdiol, methyl 3- or 5-acetoxy-[6]-gingerdiol, methyl diacetoxy-[8]-gingerdiol, [12]-gingerdione, [8]-paradol, and [6]-shogaol (Figure 1, Table 1). All of the identified phenylpropanoids correspond to those of commercial powder of ginger extract that were described by Jolad et al. [16]. The two phenylpropanoids, [6]-gingerol and [6]-shogaol, were major constituents of the ginger extract, as the area under the peaks of these two compounds was $33.2 \%$ and $31.2 \%$, respectively, while the other phenylpropanoids were present in low amounts (Figure 1).

3.2. Cytotoxicity of Ginger Phenylpropanoids and Quercetin on BJ and HaCaT Cells. Both ginger phenylpropanoids and quercetin showed limited cytotoxicity to $\mathrm{BJ} / \mathrm{HaCaT}$ cells as their IC50 values were above maximum tested concentration $50 \mu \mathrm{g} / \mathrm{mL}$ and $50 \mu \mathrm{M}$, respectively.

3.3. Effects of Ginger Phenylpropanoids and Quercetin on Nrf2ARE Pathway. Both ginger phenylpropanoids and quercetin had marked profound effects on luciferase activity of BJ and HaCaT ARE reporter cells. The average luciferase activity of BJ ARE reporter cells treated by ginger phenylpropanoids and quercetin was greater than that of their controls by 3.5 and 2.3 times, respectively (in both cases, $p<0.025$, Figure $2(\mathrm{a})$ ). The average luciferase activity of $\mathrm{HaCaT} \mathrm{ARE}$ reporter cells treated by ginger phenylpropanoids and quercetin was greater than that of their controls by 4.9 and 19.9 times, respectively (in both cases, $p<0.025$, Figure 3(a)). Western blot analyses showed that the average levels of GSTP1 protein in the BJ cells treated with ginger phenylpropanoids and quercetin were 6.5 and 2.6 times greater than that of their controls, respectively (in both cases, $p<0.025$, Figure 2(b)). The average level of this protein did not differ significantly neither between the $\mathrm{HaCaT}$ cells treated by ginger phenylpropanoids and quercetin and that of their controls ( $p$ values for effects of ginger phenylpropanoids and quercetin were $p=0.79$ and 0.87 , Figure 3(b)). Comparing controls of $\mathrm{HaCaT}$ and $\mathrm{BJ}$ cells showed that its expression level was significantly higher in HaCaT cells $(p<0.025$, Supplementary Figure 1, in Supplementary Material available online at http://dx.doi.org/10.1155/2016/2173275). 


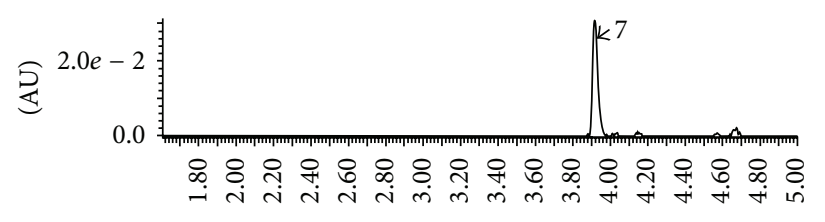

Retention time (min)

(a) HPLC-PDA chromatogram $(370 \mathrm{~nm})$

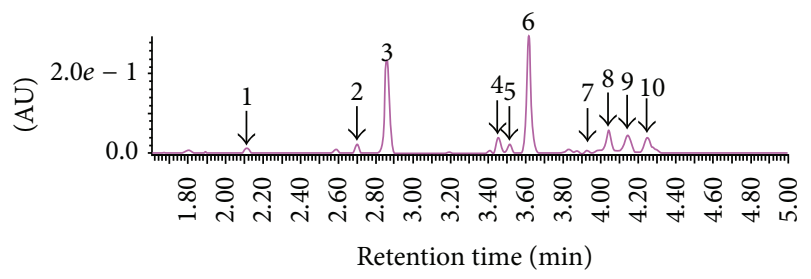

(c) HPLC-PDA chromatogram $(230 \mathrm{~nm})$

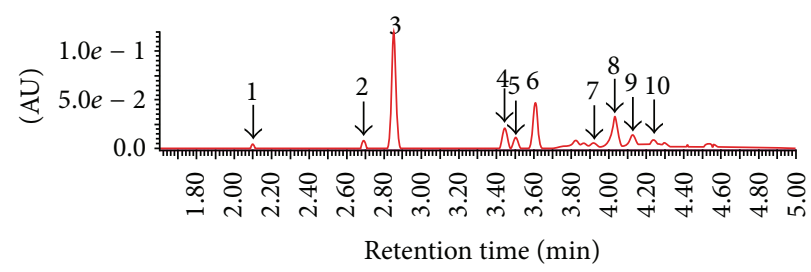

(b) HPLC-PDA chromatogram $(280 \mathrm{~nm})$

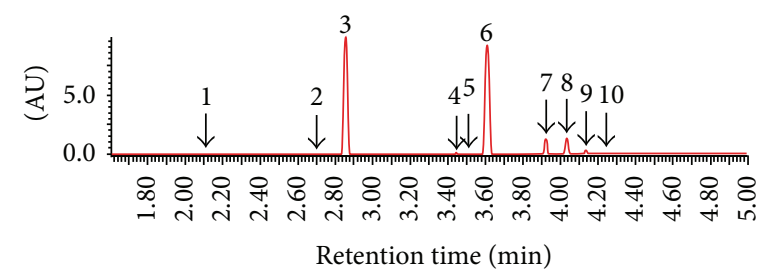

(d) Sum HPLC-PDA chromatogram (230-370 nm)

FIGURE 1: UHPLC-MS analyses of ginger methanol extract. (a), (b), and (c) are HPLC-PDA chromatograms of ginger methanol extract at 370 , 280 , and $230 \mathrm{~nm}$, respectively. (d) is a Sum HPLC-PDA chromatogram in interval (230-370 nm) detected wavelength. All of the compounds were detected in negative ion mode ionization. Peaks with the identified phenylpropanoids are listed in Table 1 . AU denotes absorbance units.

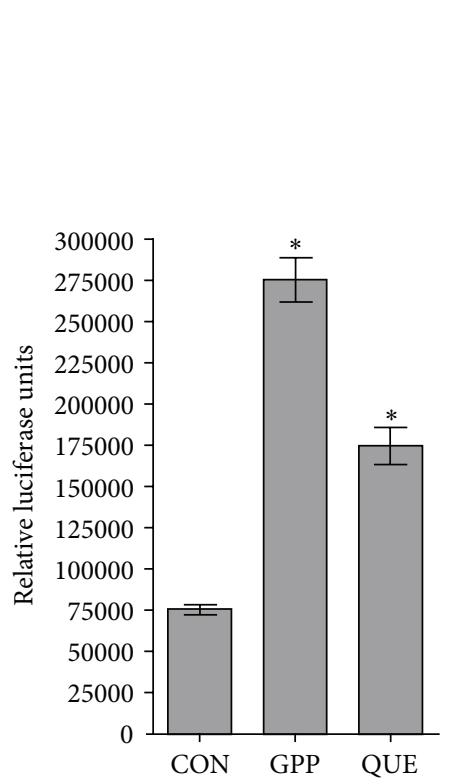

(a)
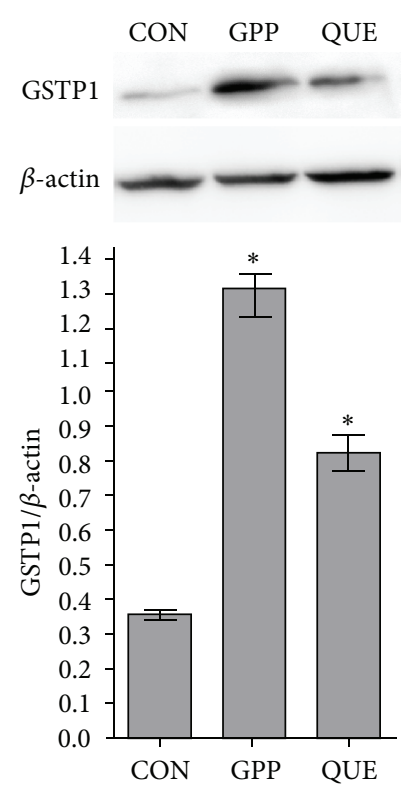

(b)

FIGURE 2: (a) Effects of ginger phenylpropanoids and quercetin on Nrf2 antioxidant pathway of luciferase ARE reporter BJ fibroblasts. (b) Western blot analysis of GSTP1 protein expression of treated BJ fibroblasts. CON, GPP, and QUE denote vehicle controls with 0.05\% DMSO, ginger phenylpropanoids, and quercetin, respectively. In the graphs, $*$ means a statistically significant value from that of controls $(p<0.025)$. Western blots were done as three biological replicates.

\section{Discussion}

Our analyses showed that both ginger phenylpropanoids and quercetin might have profound effects on Nrf2 signalling pathway in human skin cells. Both ginger phenylpropanoids and quercetin increased level of Nrf2 both in BJ and in $\mathrm{HaCaT}$ cells (Figures 2 and 3 ). These results are also consistent with previous studies that showed the effects of ginger phenylpropanoids and quercetin in the protection against oxidative stress in human skin cells [20-22]. Therefore, the studied ginger phenylpropanoids and quercetin have significant chemoprotective activity.

Specifically, in contrast to increased levels of both $\mathrm{Nrf} 2$ and its downstream target effector GSTP1 enzyme in BJ cells treated by ginger phenylpropanoids and quercetin (Figure 2(b)), the increased level of Nrf2 on treated HaCaT cells was not associated with an increased level of GSTP1 enzyme (Figure 3(b)). Such a discrepancy between the increased level of $\mathrm{Nrf} 2$ and its downstream effectors in $\mathrm{HaCaT}$ cells was also reported in previous studies of Zhang et al., [23] 


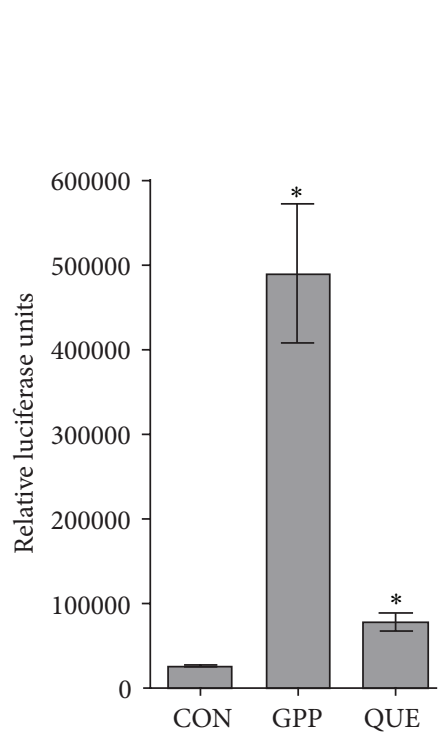

(a)

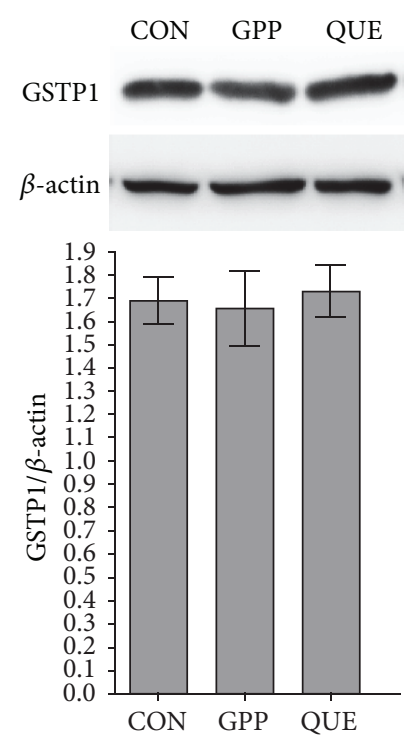

(b)

FIGURE 3: (a) Effects of ginger phenylpropanoids and quercetin on antioxidant pathway of luciferase ARE reporter HaCaT cells. (b) Western blot analyses of GSTP1 protein expression of treated HaCaT cells. CON, GPP, and QUE denote vehicle controls with $0.05 \%$ DMSO, ginger phenylpropanoids, and quercetin, respectively. In the graphs, $*$ means a statistically significant value from that of controls $(p<0.025)$. Western blots were done as three biological replicates.

and it is considered that the unknown intrinsic factors might render ARE sequence of these genes unresponsive to Nrf2. Independent regulation of GSTP1 expression in different mouse embryonic tissues by Nrf2 inducers like ethoxyquin and butylated hydroxyanisole was also suggested by the in vivo work [24].

The Nrf2 independent regulation of GSTP1 expression in $\mathrm{HaCaT}$ cells might have selectively evolved with high proliferation capacity during immortalization. As immortalization is also a first step of carcinogenesis and a variety of human cancer cells including breast, colon, kidney, lung, and ovarian cancer cells share not only genomic instability, loss of senescence genes, mutation in p53 genes, and high proliferation rate but also the constitutively high expression of GSTP1 [25-27], the role of GSTP1 in HaCaT cells might be distinct from that of the normal cells. This is also supported by the fact that, in addition to its enzyme activity in the conjugation of reduced glutathione to a wide variety of electrophilic substrates, GSTP1 was also found to inhibit the two important nonsubstrate ligands by direct proteinprotein interactions, c-Jun N-terminal kinase (JNK) and TNF receptor-associated factor 2 (TRAF2), a member of the TNF receptor-associated factor protein of JNK and p38-MAPK signalling complexes [28-30]. As these two MAP kinases are associated with signalling pathways of stress response and apoptosis [30-32], their inhibition by the high level of GSTP1 might be beneficial in inhibition of apoptosis and maintenance of high proliferation rate in $\mathrm{HaCaT}$ cells.

\section{Conclusions}

Both ginger phenylpropanoids and quercetin have property of activating the Nrf2 and expression of downstream target enzyme GSTP1 in BJ cells. On the other hand, while both ginger phenylpropanoids and quercetin can activate Nrf2 in $\mathrm{HaCaT}$ cells, their effects on expression of the GSTP1 were not mediated. This finding is in accordance with previous studies that showed that the ARE sequences in the promoter of GSTP1 gene are unresponsive to Nrf2 in HaCaT cells.

\section{Conflict of Interests}

The authors declare that there is no conflict of interests regarding publication of this paper.

\section{Acknowledgments}

The authors thank Andrew Bagshaw (School of Medicine, University of Otago, Christchurch, New Zealand) and Martin Mistrik (Institute of Molecular and Translational Medicine, Palacky University). The research was supported by the European Social Fund and the State Budget of the Czech Republic, Project no. CZ.1.07/2.3.00/30.0004 (POST-UP I), National Sustainability Programme (LO1304), and Czech Technology Agency (TE02000058).

\section{References}

[1] B. K. Armstrong and A. Kricker, "The epidemiology of UV induced skin cancer," Journal of Photochemistry and Photobiology B: Biology, vol. 63, no. 1-3, pp. 8-18, 2001.

[2] J. D'Orazio, S. Jarrett, A. Amaro-Ortiz, and T. Scott, "UV radiation and the skin," International Journal of Molecular Sciences, vol. 14, no. 6, pp. 12222-12248, 2013.

[3] T. H. Rushmore and A.-N. T. Kong, "Pharmacogenomics, regulation and signaling pathways of phase I and II drug 
metabolizing enzymes," Current Drug Metabolism, vol. 3, no. 5, pp. 481-490, 2002.

[4] F. Oesch, E. Fabian, K. Guth, and R. Landsiedel, "Xenobioticmetabolizing enzymes in the skin of rat, mouse, pig, guinea pig, man, and in human skin models," Archives of Toxicology, vol. 88, no. 12, pp. 2135-2190, 2014.

[5] T. A. Beyer, U. Auf dem Keller, S. Braun, M. Schäfer, and S. Werner, "Roles and mechanisms of action of the Nrf2 transcription factor in skin morphogenesis, wound repair and skin cancer," Cell Death and Differentiation, vol. 14, no. 7, pp. 1250-1254, 2007.

[6] E. V. Knatko, S. H. Ibbotson, Y. Zhang et al., "Nrf2 activation protects against solar-simulated ultraviolet radiation in mice and humans," Cancer Prevention Research, vol. 8, no. 6, pp. 475486, 2015.

[7] T. Nguyen, P. Nioi, and C. B. Pickett, “The Nrf2-antioxidant response element signaling pathway and its activation by oxidative stress," The Journal of Biological Chemistry, vol. 284, no. 20, pp. 13291-13295, 2009.

[8] S. Magesh, Y. Chen, and L. Hu, "Small molecule modulators of Keap1-Nrf2-ARE pathway as potential preventive and therapeutic agents," Medicinal Research Reviews, vol. 32, no. 4, pp. 687726, 2012.

[9] Y.-J. Surh, J. K. Kundu, and H.-K. Na, "Nrf2 as a master redox switch in turning on the cellular signaling involved in the induction of cytoprotective genes by some chemopreventive phytochemicals," Planta Medica, vol. 74, no. 13, pp. 1526-1539, 2008.

[10] A. Giudice, C. Arra, and M. C. Turco, "Review of molecular mechanisms involved in the activation of the Nrf2-ARE signaling pathway by chemopreventive agents," Methods in Molecular Biology, vol. 647, pp. 37-74, 2010.

[11] K.-S. Chun, J. Kundu, J. K. Kundu, and Y.-J. Surh, “Targeting Nrf2-Keap1 signaling for chemoprevention of skin carcinogenesis with bioactive phytochemicals," Toxicology Letters, vol. 229, no. 1, pp. 73-84, 2014.

[12] S. Dugasani, M. R. Pichika, V. D. Nadarajah, M. K. Balijepalli, S. Tandra, and J. N. Korlakunta, "Comparative antioxidant and anti-inflammatory effects of [6]-gingerol, [8]-gingerol, [10]gingerol and [6]-shogaol," Journal of Ethnopharmacology, vol. 127, no. 2, pp. 515-520, 2010.

[13] N. E. Fusenig and P. Boukamp, "Multiple stages and genetic alterations in immortalization, malignant transformation, and tumor progression of human skin keratinocytes," Molecular Carcinogenesis, vol. 23, no. 3, pp. 144-158, 1998.

[14] H. Jiang, B. N. Timmermann, and D. R. Gang, "Characterization and identification of diarylheptanoids in ginger (Zingiber officinale Rosc.) using high-performance liquid chromatography/electrospray ionization mass spectrometry," Rapid Communications in Mass Spectrometry, vol. 21, no. 4, pp. 509-518, 2007.

[15] M. E. Swartz and B. Murphy, "New frontiers in chromatography," American Laboratory, vol. 37, no. 3, pp. 22-27, 2005.

[16] S. D. Jolad, R. C. Lantz, G. J. Chen, R. B. Bates, and B. N. Timmermann, "Commercially processed dry ginger (Zingiber officinale): composition and effects on LPS-stimulated $\mathrm{PGE}_{2}$ production," Phytochemistry, vol. 66, no. 13, pp. 1614-1635, 2005.

[17] M.-J. Bak, S. Ok, M. Jun, and W.-S. Jeong, "6-Shogaol-rich extract from ginger up-regulates the antioxidant defense systems in cells and mice," Molecules, vol. 17, no. 7, pp. 8037-8055, 2012.
[18] Y. Yamazaki, K. Egawa, K. Nose, S. Kunimoto, and T. Takeuchi, "HIF-1-dependent VEGF reporter gene assay by a stable transformant of CHO cells," Biological and Pharmaceutical Bulletin, vol. 26, no. 4, pp. 417-420, 2003.

[19] R. Hrabakova, M. Kollareddy, J. Tyleckova et al., "Cancer cell resistance to aurora kinase inhibitors: identification of novel targets for cancer therapy," Journal of Proteome Research, vol. 12, no. 1, pp. 455-469, 2013.

[20] J. K. Kundu, H.-K. Na, and Y.-J. Surh, "Ginger-derived phenolic substances with cancer preventive and therapeutic potential," Forum of Nutrition, vol. 61, pp. 182-192, 2009.

[21] Y. Yin, W. Li, Y.-O. Son et al., "Quercitrin protects skin from UVB-induced oxidative damage," Toxicology and Applied Pharmacology, vol. 269, no. 2, pp. 89-99, 2013.

[22] J.-K. Kim, K.-M. Na, Y.-J. Surh, Y. Kim, and T.-Y. Kim, "[6]Gingerol prevents UVB-induced ROS production and COX-2 expression in vitro and in vivo," Free Radical Research, vol. 41, no. 5, pp. 603-614, 2007.

[23] Y. Zhang, V. Gonzalez, and M. J. Xu, "Expression and regulation of glutathione S-transferase P1-1 in cultured human epidermal cells," Journal of Dermatological Science, vol. 30, no. 3, pp. 205214, 2002.

[24] C. J. Henderson, A. W. McLaren, and C. R. Wolf, "In vivo regulation of human glutathione transferase GSTP by chemopreventive agents," Cancer Research, vol. 74, no. 16, pp. 43784387, 2014.

[25] R. E. J. Howells, K. K. Dhar, P. R. Hoban et al., "Association between glutathione-S-transferase GSTP1 genotypes, GSTP1 over-expression, and outcome in epithelial ovarian cancer," International Journal of Gynecological Cancer, vol. 14, no. 2, pp. 242-250, 2004.

[26] U. Tidefelt, A. Elmhorn-Rosenborg, C. Paul, X.-Y. Hao, B. Mannervik, and L. C. Eriksson, "Expression of glutathione transferase $\pi$ as a predictor for treatment results at different stages of acute nonlymphoblastic leukemia," Cancer Research, vol. 52, no. 12, pp. 3281-3285, 1992.

[27] Y. Yamamoto, H. Konishi, D. Ichikawa et al., "Significance of GSTP1 for predicting the prognosis and chemotherapeutic efficacy in esophageal squamous cell carcinoma," Oncology Reports, vol. 30, no. 4, pp. 1687-1694, 2013.

[28] Y. Eralp, S. Keskin, E. Akışık et al., "Predictive role of midtreatment changes in survivin, GSTP1, and topoisomerase $2 \alpha$ expressions for pathologic complete response to neoadjuvant chemotherapy in patients with locally advanced breast cancer," American Journal of Clinical Oncology: Cancer Clinical Trials, vol. 36, no. 3, pp. 215-223, 2013.

[29] V. Adler, Z. Yin, S. Y. Fuchs et al., "Regulation of JNK signaling by GSTp," The EMBO Journal, vol. 18, no. 5, pp. 1321-1334, 1999.

[30] M. Karin and E. Gallagher, "From JNK to pay dirt: jun kinases, their biochemistry, physiology and clinical importance," IUBMB Life, vol. 57, no. 4-5, pp. 283-295, 2005.

[31] Y. Wu, Y. Fan, B. Xue et al., "Human glutathione $S$-transferase P1-1 interacts with TRAF2 and regulates TRAF2-ASK1 signals," Oncogene, vol. 25, no. 42, pp. 5787-5800, 2006.

[32] E. Laborde, "Glutathione transferases as mediators of signaling pathways involved in cell proliferation and cell death," Cell Death and Differentiation, vol. 17, no. 9, pp. 1373-1380, 2010. 

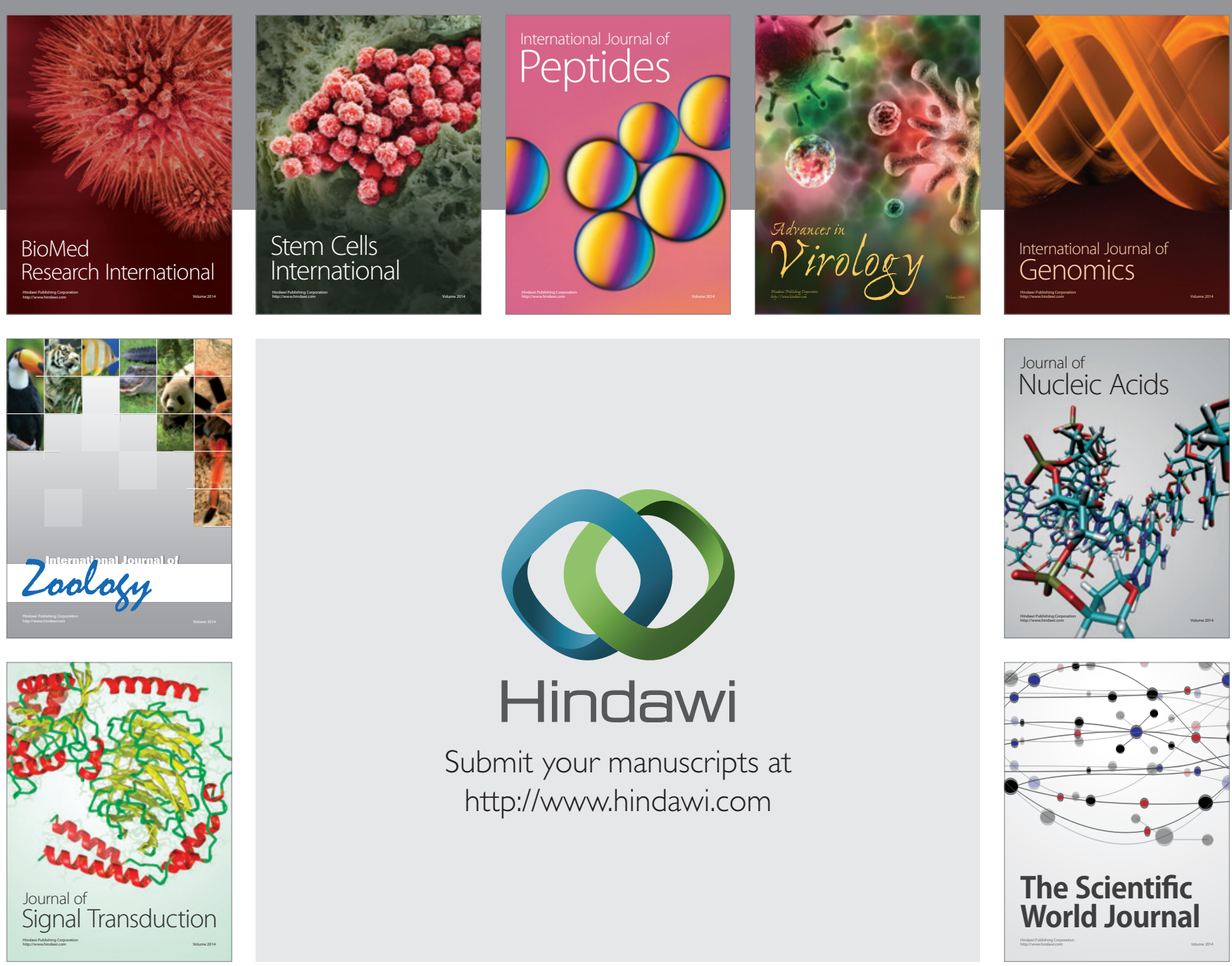

Submit your manuscripts at

http://www.hindawi.com
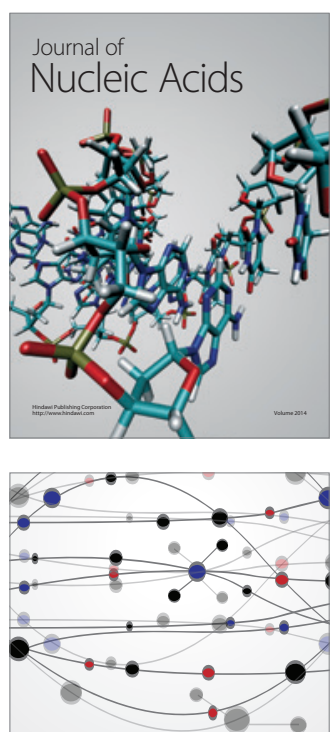

The Scientific World Journal
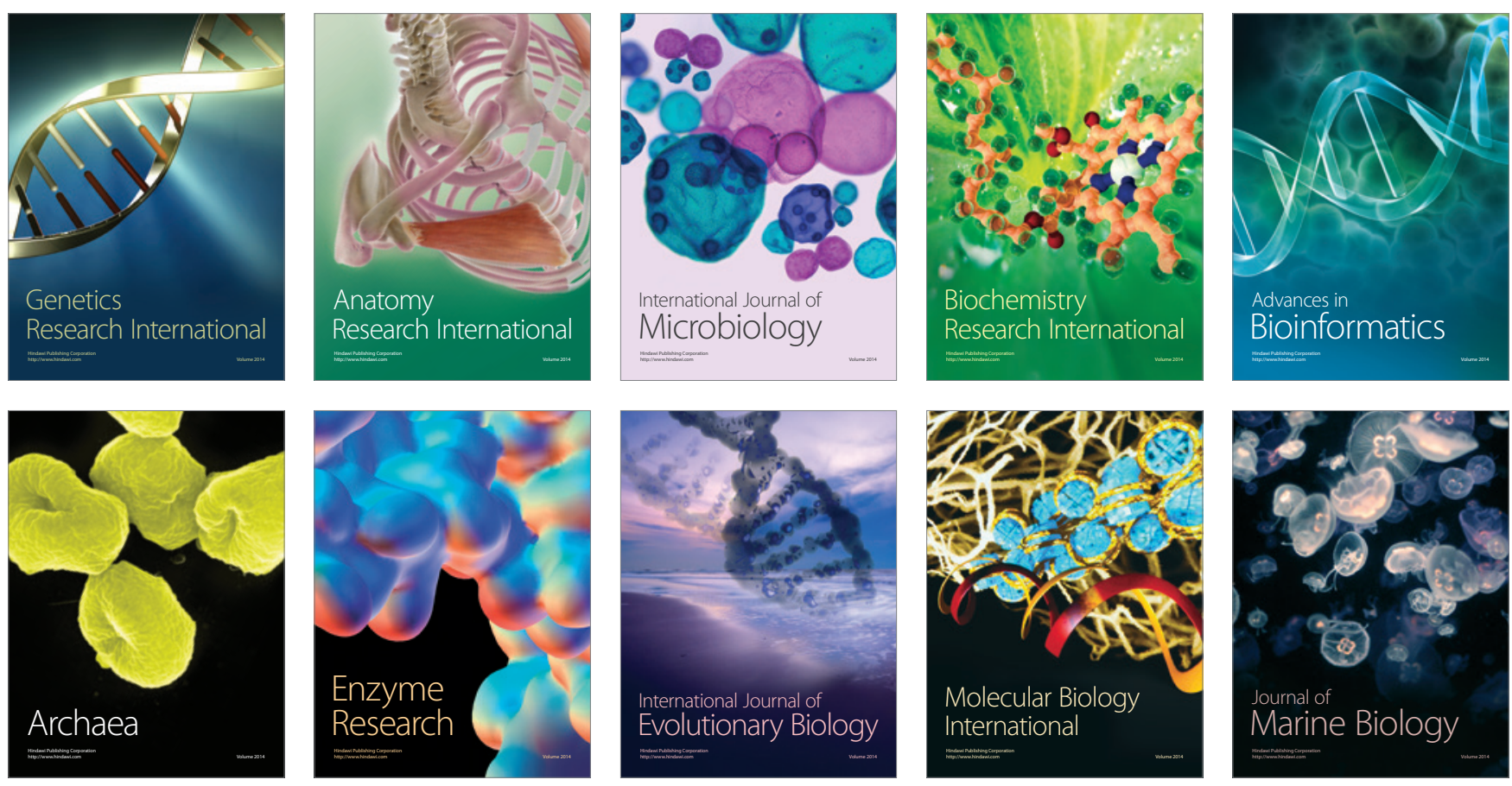